\title{
The Efficacy of Platelet-Rich Donor Plasma for the Topical Treatment of Venous Trophic Ulcers
}

\author{
Mariya V. Aralova,PhD; Aleksandr A. Glukhov,PhD, ScD; \\ Evgeniy S. Ovsyannikov, PhD*; Aleksandr N. Redkin, PhD, ScD \\ Voronezh State Medical University named after N. N. Burdenko, \\ Voronezh, the Russian Federation
}

\begin{abstract}
The purpose of the study was to evaluate the efficacy of platelet concentrate obtained from donor plasma in the local treatment of venous trophic ulcers. The study included 106 patients ( 92 women and 14 men) aged from 38 to 79 years with varicose disease of the lower extremities with the sixth stage of chronic venous insufficiency in accordance with the international clinical part of the CEAP classification. The main group included 51 patients who received donor plasma enriched with platelets $\left(10^{6}\right.$ in $\left.1 \mu l\right)$ in the local treatment. The control group consisted of 55 patients who, in the local treatment, were given only modern dressings in strict accordance with the modern concept of treatment of chronic wounds. The results of the treatment were evaluated after 10 days of medical intervention. The use of the platelet-rich donor plasma in the regional treatment of trophic ulcers of venous etiology stimulates the regeneration processes and initiates the formation of granulation tissue, epithelialization, and angiogenesis. A wide range of local therapeutic effects, stimulating the regeneration, allows reducing the treatment time, improving the quality of life of patients and reducing the cost of treatment. (International Journal of Biomedicine. 2017;7(4):289-292.)
\end{abstract}

Key Words: venous trophic ulcers $\bullet$ local treatment $\bullet$ regeneration $\bullet$ platelet-rich donor plasma

\section{Introduction}

Venous trophic ulcers (VTUs) are a big medical, social and economic problem. Treatment of patients with nonhealing wounds on the background of chronic venous insufficiency (CVI) requires significant material costs, patience and high professionalism of doctors. ${ }^{(1,2)}$ The formation of granulation tissue and epithelialization in ulcers is usually stimulated by local products. In conditions of impaired nutrition, the synthesis of tissue elements in the wound is slow. ${ }^{(3)}$ Therefore, it seems appropriate to use whatever means are available to stimulate regeneration.

Platelet-rich plasma (PRP) is increasingly being used as a new alternative approach in various fields of medicine. The curative properties of PRP rely on the fact that platelets are a physiological reservoir of a variety of growth factors, with healing function which have an active role in tissue regeneration. ${ }^{(4,5)}$

*Corresponding author: Evgeniy S. Ovsyannikov, PhD. Department of faculty therapy, Voronezh State Medical University named after N.N. Burdenko.Voronezh, Russia. E-mail: ovses@, yandex.ru.
The major platelet growth factors are: PD-EGF - epidermal growth factor of platelets, PDGF - platelet derived growth factor, BMP - bone morphogenetic protein, TGF - transforming growth factor, IGF - insulin-like growth factor, VEGF - vascular endothelial growth factor vessels, ECGF, a growth factor for endothelial cells, bFGF - basic fibroblast growth factor. The intracellular amount of endogenous growth factors is determined at the genetic level and is in a certain ratio. ${ }^{(6)}$ By acting on the receptors of the membranes of stem cells, growth factors cause their proliferation. Growth factors have an oligopeptide structure and affect cell membrane receptors type I and II, and promote the growth and differentiation of healthy progenitor cells. ${ }^{(7)}$

The commonality of biological responses in different tissues of the body to damage or the generic mechanism of the action of growth factors has provided a wide application of PRP in cosmetic, general, plastic and facial surgery, as well as in dermatology, ophthalmology, dentistry, traumatology, orthopedics, and sports medicine. ${ }^{(8-12)}$ The efficacy of autologous PRP for the restoration of damaged tissues with low healing potential has been proven. Preparation of autologous PRP requires a procedure room for blood sampling, a laboratory, 
trained medical staff and time to directly obtain PRP, which is inconvenient in outpatient centers. ${ }^{(13)} \mathrm{We}$ believe that process optimization is possible using platelet concentrates obtained from donor plasma.

The purpose of the study: to evaluate the efficacy of platelet concentrate obtained from donor plasma in the local treatment of VTUs.

\section{Materials and methods}

The study included 106 patients (92 women and 14 men) aged from 38 to 79 years (average age of $64.2 \pm 16.4$ years) with varicose disease of the lower extremities with the sixth stage of CVI in accordance with the international clinical part of the CEAP classification.

The study protocol was reviewed and approved by the Ethics Committee of Voronezh State Medical University named after N. N. Burdenko, All participants provided the written informed consent.

The inclusion criteria were men or women aged 20-80 years, venous trophic ulcer of the lower extremities (area less $20 \mathrm{~cm}^{2}$ ), the phase 2 of chronic wound process, ankle brachial index $(\mathrm{ABI}) \geq 0.8$ and $\leq 1.2$, informed consent form signed.

The exclusion criteria were chronic infectious diseases, treatment with radiotherapy or chemotherapy, history of cancer, ABI $<0.8$ or $>1.2$, the phase 1 of chronic wound process, low compliance of patients, diabetes, decompensated heart failure, systemic diseases of connective tissue, hormone therapy, lymphedema, pregnancy.

The duration of existence of trophic ulcers was $5.3 \pm 1.4$ years (from 4 months to 8 years). The period of time for open sores was from 3 months to 6 years, an average of $1.8 \pm 0.36$ years. The average size of VTU was $14.6 \pm 3.2 \mathrm{~cm}^{2}$ (from 8.0 to $20 \mathrm{~cm}^{2}$ ). The non-healing ulcers were first debrided to remove any necrotic tissues and fibrin. In all patients, clinical examination showed that the wound was consistent with the phase 2 of chronic wound process: at the bottom of the wounds there were sluggish single granulations, areas covered with fibrin, and the epithelialization edge was not expressed. Bacteriological monitoring revealed mainly S. aureus, S. epidermidis, and E. coli bacterial contamination not higher than $10^{3} \mathrm{CFU} / \mathrm{g}$. Cytological examination was consistent with an inflammatory type of cytogram. Patients randomly were divided into main and control groups.

The main group (MG) included 51 patients who received donor plasma enriched with platelets $\left(10^{6}\right.$ in $\left.1 \mu \mathrm{l}\right)$ in the local treatment. PRP was obtained with the Trima Accel Automated Blood Collection System Version 6.0. The main requirements for alloplatelets are infectious and immunological safety, which are achieved by:

- screening of blood-borne infections

- a reduction of immunological risks

- maintenance of an adequate stock of platelet concentrate

- timely delivery of the corresponding platelet

concentrates

- monitoring and prevention of side effects

Immediately before using the platelet-rich donor plasma (PRDP), a 10\% calcium chloride solution $(2 \mathrm{ml}$ per $20 \mathrm{ml}$ of
PRDP) was added to it to activate platelets. The composition was mixed slowly until a thick, uniform mass was formed, which was injected into the bottom and edges of the wound. The wound was closed with a bandage supporting the moist environment in the wound.

The control group consisted of 55 patients who, in the local treatment, were given only modern dressings in strict accordance with the modern concept of treatment of chronic wounds.

In all patients before the study and in the dynamics, the size of the ulcer was evaluated with the help of the vector-raster editor Spotlight Pro 10 (CSoft), the condition of the skin around the ulcer was assessed, and bacteriological and cytological studies were performed. All patients underwent ultrasonic duplex scanning, ultrasound examination of soft tissues, computed tomography (CT) scanning, magnetic resonance imaging (MRI), and transcutaneous oxygen measurement.

The results of the treatment were evaluated after 10 days of medical intervention. During the registration, processing and analysis of digital material, we used Microsoft Excel and Microsoft Word. All values are presented as mean \pm standard deviation or as number (percentage). The intergroup comparisons were performed using Student's t-test. A probability value of $\mathrm{P}<0.05$ was considered statistically significant.

\section{Results}

In the study group, after 10 days treatment, 43(84\%) patients reported reduction in pain, heavy legs, swelling, wound pain, and cramps in the calf muscles. A maceration of the skin around venous ulcers was observed in 5(9.8\%) patients. In $41(80 \%)$ patients, bright juicy granulations appeared, covering almost the entire bottom and forming a distinct cushion of boundary epithelialization; on average, the area of trophic ulcers for the group decreased by $4.3 \mathrm{~cm}^{2}$ $(P<0.05)$ due to the boundary epithelialization (Fig.1).

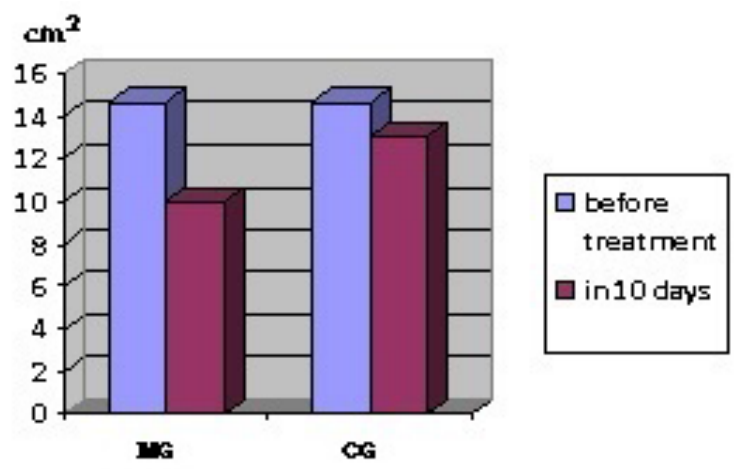

Fig. 1. Dynamics of the area of wounds

In $10(19.6 \%)$ patients, significant dynamics in the area and the state of wounds was not marked, granulation was sluggish, and epithelialization was slow. Microbiological monitoring revealed complete bacterial elimination in 44(86\%) 
of patients. In $7(14 \%)$ patients we found opportunistic strains in the wound, bacterial contamination of which did not exceed $10^{2}-10^{3}$ microbial cells. A cytological study revealed the regenerative type of cytogram in $41(80 \%)$ patients and the inflammatory type in $10(20 \%)$ cases.

In the control group, after 10 days treatment, 39(71\%) of patients reported a reduction in pain and in the burning sensation in the wound area, and painless dressings. In the objective assessment, 32(58\%) patients showed granulation and marginal epithelialization. Skin maceration and perifocal inflammation were observed in $11(20 \%)$ patients. In this group, the area of trophic ulcers decreased by $1.6 \mathrm{~cm}^{2}(\mathrm{P}<0.05)$ due to the boundary epithelialization (Fig.1). In 23(42\%) of the patients, there was a marked increase in the exudation from the wound, and we took measures to protect the skin around ulcers by using an absorbent wound dressing; the wounds were still clean and actively granulated, but changes in the depth and area of the wounds were not statistically significant. During microbiological monitoring, bacterial elimination was observed in $31(56 \%)$ patients, in $21(38 \%)$ cases the wound showed pathogenic strains - $10^{2}-10^{3}$ microbial cells; we observed Pseudomonas aeruginosa in $10^{5} \mathrm{CFU} / \mathrm{g}$ in 3 patients. A cytological study revealed the regenerative type of cytogram in $32(58 \%)$ patients, the inflammatory type in $19(35 \%)$ cases, and the degenerative-inflammatory type in $4(7 \%)$ cases.

\section{Discussion}

Autologous PRP treatment is used for managing various types of lesions including corneal, vasculitic, neuropathic and diabetic foot ulcers, among others. ${ }^{(14-16)}$ Several studies using this technique have demonstrated adecrease in healing time compared to conventional treatments (in particular, the currently recommended MWC). Releasing cytokines and hemostatic factors into the tissue of the growth factors, after the destruction of platelets, induces chemotaxis of the major cell types participating in the repair processes. Histamine and serotonin, isolated by platelets, activate macrophages and increase vascular permeability, which opens access to the focus of inflammation. In the process of wound reparation, the local concentration of growth factors, cytokines and other biologically active substances plays an important role. ${ }^{(17,18)}$

The clinical efficacy of PRDP was obvious in our study; the bright juicy granulations, which filled out almost the entire bottom of the wounds with the formation of a pronounced boundary cushion epithelialization, were identified in $80 \%$ of patients of the main group and only in $58 \%$ of the control group. The investigation of the wound area in dynamics revealed that the application of PRDP led to a decrease in the area of the wound surface by $29 \%$, compared with $11 \%$ in the control group. Data from cytological studies confirmed a more rapid transition to the regenerative type of cytogram under using PRDP.

The results of the microbiological monitoring confirm that the antibacterial and fungicidal activity contained in platelets by proteases such as metalloprotease- 4 is able to prevent infection. ${ }^{(19)}$

We believe it is important to note also a positive dynamics in the subjective sensations of patients: a reduction in pain, heavy legs, swelling, wound pain, and cramps in the calf muscles.

\section{Conclusion}

Thus, the use of PRDP in the regional treatment of trophic ulcers of venous etiology stimulates the regeneration processes and initiates the formation of granulation tissue, epithelialization, and angiogenesis. A wide range of local therapeutic effects, stimulating the regeneration, allows reducing the treatment time, improving the quality of life of patients and reducing the cost of treatment.

\section{Competing interests} interests.

The authors declare that they have no competing

\section{References}

1. Aralova MV, Ostroushko AP. Prevalence of Venous Trophic Ulcers of the Lower Extremities at Inhabitants of the Voronezh Region. Vestnik of Experimental and Clinical Surgery 2015;8(2):248-251. [Article in Russian].

2. Wong IK, Andriessen A, Charles HE, Thompson D, Lee DT, So WK et al. Randomized controlled trial comparing treatment outcome of two compression bandaging systems and standard care without compression in patients with venous leg ulcers. J Eur Acad Dermatol Venereol. 2012;26(1):102-10. doi: 10.1111/j.1468-3083.2011.04327.x

3. Gluhov AA, Aralova MV. Pathophysiology of persistent chronic wounds and current methods of stimulation of wound process. Novosti Khirurgii. 2015;23(6):673-679. doi: http:// dx.doi.org/10.18484/2305-0047.2015.6.673. [Article in Russian]. 4. Andia I, Abate M. Platelet-rich plasma: underlying biology and clinical correlates. Regen Med. 2013;8(5):64558. doi: 10.2217/rme.13.59.

5. Suthar M, Gupta S, Bukhari S, Ponemone V. Treatment of chronic non-healing ulcers using autologous platelet rich plasma: a case series. J Biomed Sci. 2017;24(1):16. doi: 10.1186/s12929-017-0324-1.

6. Nagumo A1, Yasuda K, Numazaki H, Azuma H, Tanabe Y, Kikuchi S, et al. Effects of separate application of three growth factors (TGF-beta1, EGF, and PDGF-BB) on mechanical properties of the in situ frozen-thawed anterior cruciate ligament. Clin Biomech (Bristol, Avon). 2005; 20(3):283-90.

7. Kasemkijwattana C1, Menetrey J, Bosch P, Somogyi G, Moreland MS, Fu FH, et al. Use of growth factors to improve muscle healing after strain injury. Clin Orthop Relat Res. 2000; (370):272-85.

8. Malanin DA, Novochadov VV, Demkin SA, Demidenko MV, Danilov DI. Autologous platelet-rich plasma in the treatment of patients with knee arthritis III stage. Traumatology and Orthopedics of Russia 2014;3(73):52-59. [Article in Russian].

9. Mastikov AN, Wasdeikalo VP, Samsonova IV, Boloboshko KB. Efficacy of platelet-rich plasma in the treatment of traumatic cartilage defects of articular surfaces. News surgery. 2013;21:3-9. [Article in Russian].

10. Burnouf T, Strunk D, Koh MB, Schallmoser K. Human platelet lysate: Replacing fetal bovine serum as a gold standard 
for human cell propagation? Biomaterials. 2016;76:371-87. doi: 10.1016/j.biomaterials.2015.10.065.

11. Molloy T, Wang Y, Murrell G. The roles of growth factors in tendon and ligament healing. Sports Med 2003; 33(5):381-94. 12. Sánchez M1, Anitua E, Azofra J, Aguirre JJ, Andia I. Intra-articular injection of an autologous preparation rich in growth factors for the treatment of knee OA: a retrospective cohort study. Clin Exp Rheumatol. 2008: 26(5):910-3.

13. Gubanov MN, Kopchenko TG, Zhiburt EB. The choice of the method of producing a concentrate of platelets of the whole blood. Vestnik Sluzby Krovi Rossii. 2009;3:20-22. [Article in Russian].

14. Tzeng YS, Deng SC, Wang CH, Tsai JC, Chen TM, Burnouf T. Treatment of nonhealing diabetic lower extremity ulcers with skin graft and autologous platelet gel: a case series. Biomed Res Int. 2013; 2013:837620 doi: 10.1155/2013/837620.

15. Suryanarayan S, Budamakuntla L, Sha Khadri SI, Sarvajnamurthy S. Efficacy of autologous platelet-rich plasma in the treatment of chronic nonhealing leg ulcers. Plastic Aesthetic Res 2014, 1(2):65-69. Informe V1/23052013.
16. San Sebastian KM, Lobato I, Hernández I, Burgos-Alonso N, Gomez-Fernandez MC, López JL, et al. Efficacy and safety of autologous platelet rich plasma for the treatment of vascular ulcers in primary care: Phase III study.BMC Fam Pract. 2014 Dec 30;15:211. doi: 10.1186/s12875-014-0211-8.

17. Foster TE, Puskas BL, Mandelbaum BR, Gerhardt MB, Rodeo SA. Platelet-rich plasma: from basic science to clinical applications. Am J Sports Med. 2009;37(11):2259-72. doi: 10.1177/0363546509349921.

18. Gluhov AA, Aralova MV. Evaluating the effectiveness of a combination of concentrated platelets and suspension of native collagen unreconstructed for the topical treatment of trophic ulcers of the small and medium-sized. Vestnik of Experimental and Clinical Surgery 2016;9(4):275-280. [Article in Russian].

19. Moshiri A1, Oryan A2, Meimandi-Parizi A1, Silver IA3, Tanideh N4, Golestani N1. Effectiveness of hybridized nanoand microstructure biodegradable, biocompatible, collagenbased, three-dimensional bioimplants in repair of a large tendon-defect model in rabbits.J Tissue Eng Regen Med. 2016 Jun;10(6):451-65. doi: 10.1002/term.1740. 